\title{
CORRECTION
}

\section{Correction to: Treatment decision-making in sickle cell disease patients}

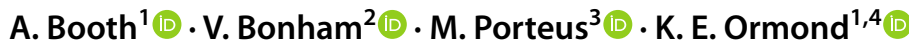

Published online: 23 December 2021

○) Springer-Verlag GmbH Germany, part of Springer Nature 2021

Correction to: Journal of Community Genetics https://doi.org/10.1007/s12687-021-00562-z

The original version of this article unfortunately contained a mistake..

In Figure 1c legend, "beneficial treatment" should read "dangerous treatment". The correct figure is shown below.

This is being corrected in this publication.

Publisher's note Springer Nature remains neutral with regard to jurisdictional claims in published maps and institutional affiliations.

The original article can be found online at https://doi.org/10.1007/ s12687-021-00562-z.

K. E. Ormond

kormond@stanford.edu; Kelly.ormond@hest.ethz.ch

1 Department of Genetics, Stanford School of Medicine, Stanford, CA, USA

2 National Human Genome Research Institute, Bethesda, MD, USA

3 Department of Pediatrics, Stanford School of Medicine, Stanford, CA, USA

4 Stanford Center for Biomedical Ethics, Stanford School of Medicine, Stanford, CA, USA 
Fig. 1 a Displays the likelihood of participants to choose each individual treatment. b Displays the perceptions of benefit that the participants felt about each treatment. c Displays the perception of danger that the participants felt about each treatment a Likelihood of Choosing a Curative Option

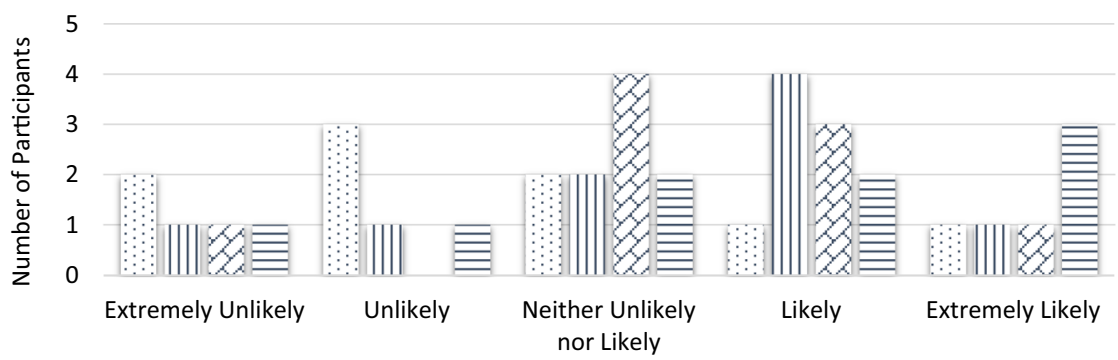

: Stem Cell Transplant

II Gene therapy to add a new healthy gene

$>$ Fetal hemoglobin gene editing

$\equiv$ Gene correction gene editing

b

Perception of Benefit

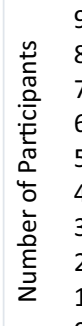

$$
8
$$

Strongly disagree Disagree

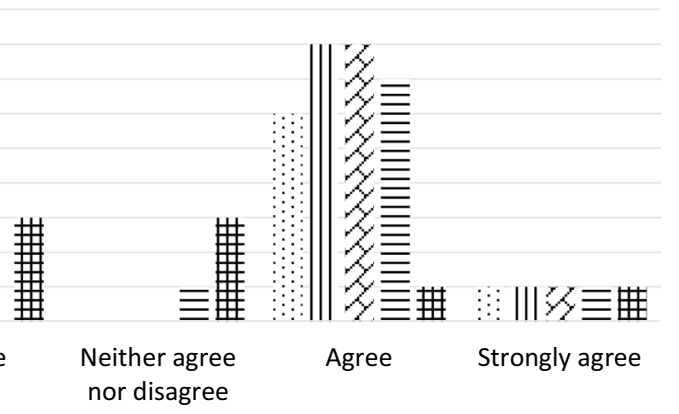

:: Stem cell transplant is a beneficial treatment

II Gene therapy to add a new healthy gene is a beneficial treatment

$\checkmark$ Fetal hemoglobin gene editing is a beneficial treatment

$=$ Gene correction gene editing is a beneficial treatment

$\#$ Not receiving any of these treatments is beneficial

c

\section{Perception of Danger}

\section{5}

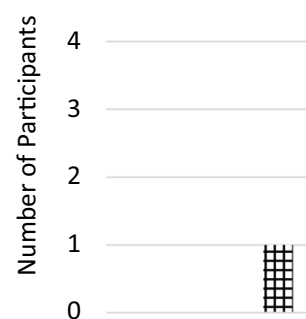

Strongly disagree
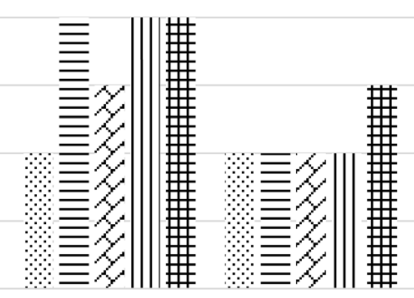

Disagree

Neither agree nor disagree

$\therefore$ Stem cell transplant is a dangerous treatment

= Gene therapy to add a new healthy gene is a dangerous treatment

$\varsigma$ Fetal hemoglobin gene editing is a dangerous treatment

III Gene correction gene editing is a dangerous treatment

$\sharp$ Not receiving any of these treatments is a dangerous treatment 